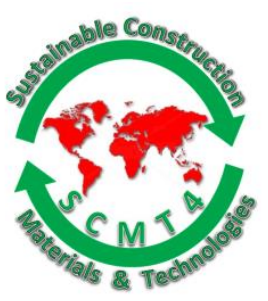

SCMT4

Las Vegas, USA, August 7-11, 2016

\title{
Prediction Method for the Initiation of the Spalling of the Cover Concrete of RC Bridges in Service
}

\author{
Shuntaro Todoroki ${ }^{1 a}$, and Ken Watanabe ${ }^{1 b}$ \\ ${ }^{1}$ Concrete structures, Structures Technology Division, Railway Technical Research Institute - 2-8-38, \\ Hikari-cho, Kokubunji-shi, Tokyo, 180-8540, Japan. \\ ${ }^{1 a}$ Email: <todoroki.shuntaro.73@rtri.or.jp>, ${ }^{1 b}$ Email: 〈watanabe.ken.08@rtri.or.jp>.
}

\begin{abstract}
The objective of this study is to predict the initiation of the spalling of the cover concrete of RC bridges by estimating the rebar corrosion rate. The rebar corrosion rate was studied based on the developed estimation method by means of the visual observation of such phenomena as the spalling of the cover concrete of the columns and barriers of railway RC bridges in service. The result indicated that the rebar corrosion rate in wet condition was 2.2 times faster than that in dry condition, and the effect of dry-wet condition to the rebar corrosion rate was larger than that of cover depth and uncarbonated depth. In addition, based on the existing equation of the rebar corrosion rate in consideration of the dry-wet condition of concrete, the corrosion rate of these RC bridges in service was estimated on the assumption that the water content is $5 \%$ at the concrete surface in case of wet condition which is recognized by the existence of the water-bearing mark, and on the assumption that the water content is $2-4 \%$ at the concrete surface in case of dry or dry-wet condition. By means of the proposed method which is based on the estimation of the rebar corrosion rate, it is possible to predict the initiation of the spalling of the cover concrete of RC bridges in service.
\end{abstract}

\section{INTRODUCTION}

One of the deterioration factors for RC structures is the rebar corrosion caused by a chloride ion and the carbonation of concrete. The rebar corrosion induces the cracking and spalling of cover concrete. Especially, the spalling of cover concrete will deteriorate not only the structural performance and the appearance but also the margin for the safety of residents around the RC structures, the structures should be repaired appropriately. The spalling of cover concrete is usually detected based on the visual observation and the hammer tapping. However, in this method, a lot of engineers with empirical knowledge are required. So, it is not a reasonable way of maintaining RC structures. If it is possible to decide when to survey and when to repair RC structures based on a quantitative prediction method of the spalling of the cover concrete caused by corrosion, it will achieve reasonable asset management of RC structures.

Previous researches for the prediction of the rebar corrosion have proposed a theoretical equation based on a thermos-dynamics coupled model [Maekawa et al. 2008] or micro-macro cell corrosion model [Maruya et al. 2006], and an experimental equation [Iijima et al. 2009; Kakegawa et al. 2012] based on constant 
temperature and humidity condition tests, and natural exposure tests. For deterioration by carbonation and salt injury, a macro model [Tottori et al. 2006] in which the deterioration process such as the cracking and spalling of concrete is taken into account was proposed, and showed in [RTRI 2007]. Since this model was proposed based on a study under a certain environmental condition, it is not possible to perfectly predict, by using this model, all the phenomena of the concrete of bridges in service which are exposed to various environmental conditions. Therefore, it is important to pick up large impact factors in deterioration and to take them into consideration in case of the construction of the macro model in order to upgrade the precision of the deterioration prediction.

In this study, field survey was carried out for the columns and barriers of railway RC bridges which had the spalling of cover concrete due to deterioration by carbonation or composite deterioration by carbonation and salt injury. Environmental, material and constructional conditions in bridges were suggested by visual observation and carbonation depth. The rebar corrosion rate was estimated based on the deterioration such as the spalling of cover concrete judged by visual observation, and the impact of each factor on the rebar corrosion rate was examined. Also, by using the equation of the rebar corrosion rate [iijima et al. 2009] in consideration of water content at the concrete surface, surface water content is calculated based on the deterioration judged by visual observation, and a study of the rebar corrosion rate is performed. Based on the estimated rebar corrosion rate, a prediction method of the initiation of the spalling of the cover concrete of $\mathrm{RC}$ bridges in service is proposed.

\section{OUTLINE OF THE SURVEY}

\section{Bridges for survey}

Table 1 shows the detail of the bridges for the survey. These bridges are RC rigid frame viaducts $\mathrm{A}, \mathrm{B}$. The age at the time of the survey was about 30 years. The bridges suffered deterioration such as the spalling of cover concrete by the rebar corrosion.

Table 1. Bridges for the Survey

\begin{tabular}{|c|c|c|c|}
\hline Viaduct name & year of construction & Age at the time of survey & Target \\
\hline Viaduct A & 1973 & 36 years & Column \\
\hline Viaduct B & 1979 & 26,27 years & Barrier \\
\hline
\end{tabular}

\section{Viaduct A}

Figure 1 shows the summary of viaduct A. The member for the survey was a column. Chloride ion concentrations at the column were $0.16-0.30 \mathrm{~kg} / \mathrm{m}^{3}$ (the number of data: 3 ). No chloride ions from the sea were considered to exist because the distance from the coastal line is more than $1 \mathrm{~km}$ [RTRI 2007]. Carbonation depths are $0-32.5 \mathrm{~mm}$ (the number of data: 137). Therefore, the deterioration factor is presumed to be carbonation. The annual average of the daily average temperature and the annual average precipitation in past five years near the viaduct were 16.2 degrees in Celsius and $3347.9 \mathrm{~mm}$ respectively, according to the data provided by Japan Meterological Agency. As for the surrounding environment, on the left facing the end point there are houses and on the right there is vacant land The column on the right side is blocked by a structure for increased tracks at the time of the survey. The column on the left is affected by rain, sunlight, wind and so on. The line runs from south-southeast to north-northeast. 


\section{Viaduct B}

Figure 2 shows the summary of viaduct B. The member of the survey was a barrier. Chloride ion concentrations of 0.78 to $2.2 \mathrm{~kg} / \mathrm{m}^{3}$ were observed inside the barrier (the number of data: 124). No chloride ions from the sea were considered to exist because the distance from the coastal line is about $1.5 \mathrm{~km}$ [RTRI 2007], so the initial chloride ion is included in concrete. "Initial chloride ion" means the chloride ion contained in concrete at the time of construction by such reasons as the use of sea sand. The carbonation depths were $5.9-15.0 \mathrm{~mm}$ (the number of data: 82). Figure 3 shows the presumption of the deterioration factors by [RTRI 2007]. The deterioration factors were presumed to be both carbonation and initial chloride ion. In Figure 3, "uncarbonated depth" means the thickness obtained by subtracting the carbonation depth from the cover depth. The daily average temperature and annual average precipitation in past 5 years past were 16.2degrees in Celsius and $1974.9 \mathrm{~mm}$ respectively, according to the data provided by Japan Meteorological Agency. Although this viaduct was located in an urban area, there was nothing to block the sun light and rain. The line runs from west-northwest to east-southeast.

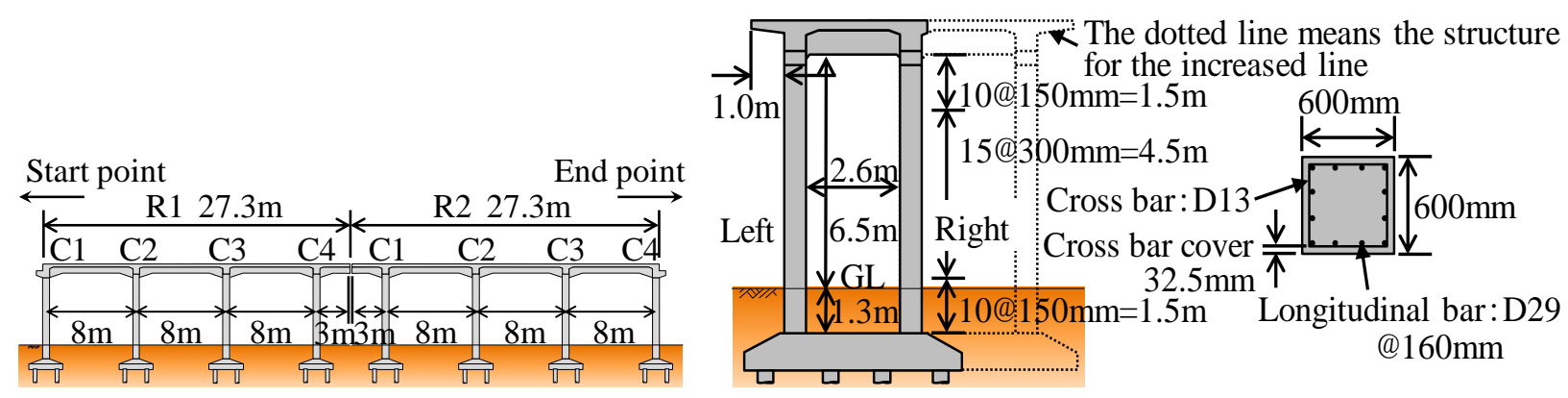

Figure 1. Summary of Viaduct A
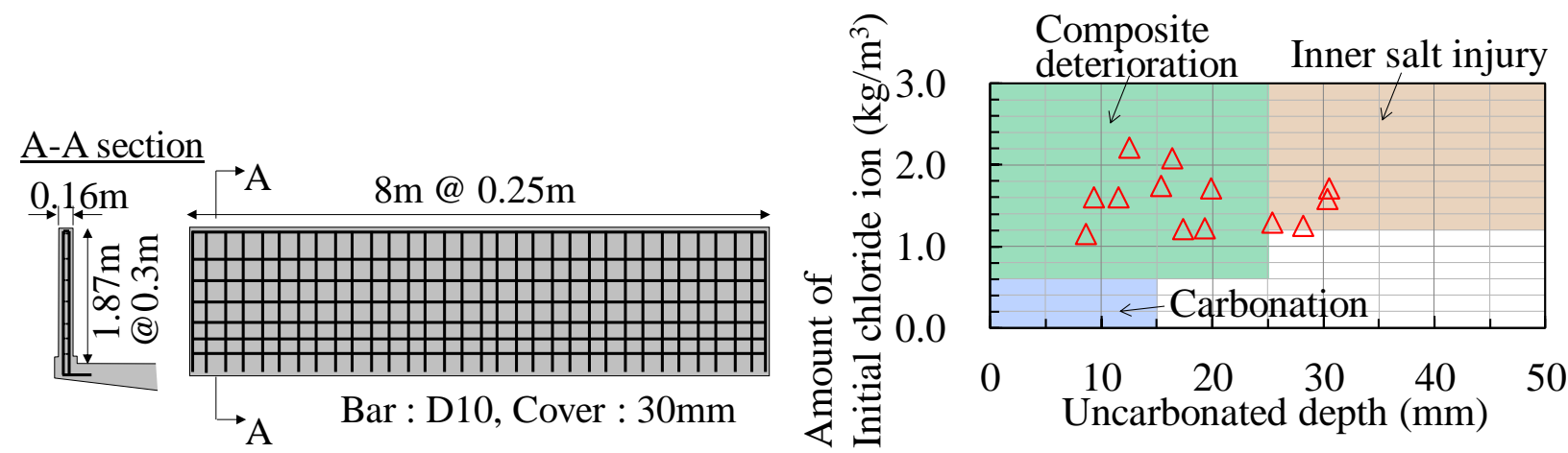

Figure 2. Summary of Viaduct B

Figure 3. Presumption of the Deterioration Factors

\section{Measurement method of deterioraion factors and measurement points}

Deterioraion depends on carbonation depth, cover depth and chloride ion concentraion. "Cover depth" means the covering thickness of a rebar. A hole with a diameter of $24 \mathrm{~mm}$ was made by drilling, and the inside of the hole was cleaned by an air spray. A solution with a phenolphthalein density of $1 \%$ was sprayed inside the hole. Finally, the distance from the concrete surface to the colored border by the above solution was measured. This distance means "Carbonation depth". This carbonation depth was measured at 4 points of up, down, left and right inside the hole, and the average value of the 4 points is defined as the carbonation depth of each hole. The cover depth was measured by the electromagnetic induction method. The chloride 
ion concentration was measured by the potentiometric titration method under which a drilled powder obtained at $80-100 \mathrm{~mm}$ depth from the concrete surface is used. Figure 4 (a) and (b) show the measurement points of the column of viaduct $A$ and those of the barrier of viaduct $B$. In the viaduct $A$, The measurement of the carbonation depth, cover depth and chloride ion concentrations was performed at each height and the 4 surfaces of the column. The cover depth of each cross rebar was measured along 2 lines. In the viaduct $\mathrm{B}$, The cover depth of each longitudinal rebar was measured along 3 lines of up, middle and down.

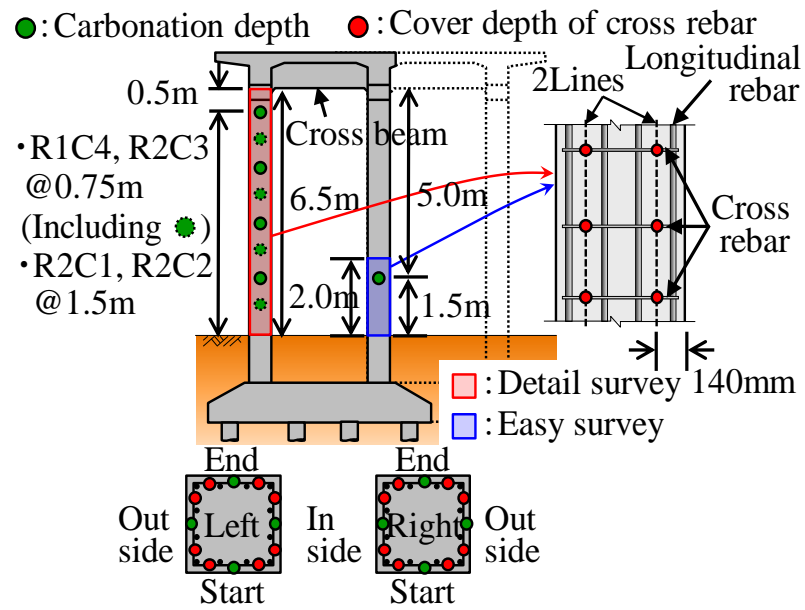

(a) Viaduct A

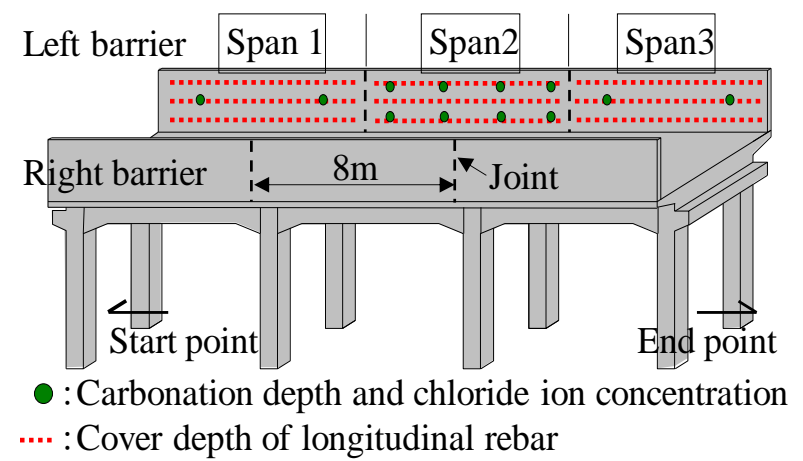

(b) Viaduct B

Figure 4. Measurement Points for Deterioration Factors

\section{Developed estimation method of the rebar corrosion rate based on visual observation}

In case of the estimation of the rebar corrosion rate of RC structures in service, it is difficult to measure the amount and the rate of the rebar corrosion. On the other hands, Information and communication Technology will realize the acquisition, the accumulation and the use of digital visual images and survey data. Therefore, the developed estimation method of the rebar corrosion rate is based on the deterioration such as the spalling of cover concrete judged by visual observation (visual deterioration) and survey data. Under this method, "the spalling rate" calculated by visual observation and that calculated by prediction are compared in order to estimate the rebar corrosion rate. In this method, a certain area of RC members is defined as the "calculation area of the spalling rate", and the ratio between the area where the spalling has occurred and the whole calculation area ( = surface area of the spalling / whole surface area) is defined as the "spalling rate".

Figure 5 shows the summary of the deterioration prediction method based on visual deterioration for viaduct A as an example. The calculation area of the spalling rate is set around the center of carbonation measurement points. In the calculation of spalling rate, the spalling of cover concrete is judged by visual observation and prediction regarding each mesh made onto the cross rebar, and the spalling rate of visual observation and that of prediction are calculated and both are compared. The prediction model used in this study is shown in [RTRI 2007]. In here, the carbonation at each mesh was uniform in the calculation area of the deterioration rate. The cover depth of the rebar of each mesh was given by interpolation and extrapolation from measured cover depths. The rebar corrosion rate was considered on two patterns as follows.

I) The rebar corrosion rate was assumed to be variable, and it is repeatedly calculated until the spalling rate obtained by visual observation becomes the same as that by prediction, and the rebar corrosion rate $v_{\text {cnd }}$ was estimated.

II) The rebar corrosion rate is caluculated by the equations (1) - (3) in consideration of the water condition 
of concrete [Iijima et al. 2009]. In here, the surface water content was calculated by the equations (1) -(3). This is how to obtain the surface water content by repeatedly calculating until the spalling rate obtained by visual observation became the same as that by prediction, and the rebar corrosion rate was estimated by it. Equations (1) - (3) [Iijima et al. 2009] are the equations of the rebar corrosion rate. The equation (1) is used in cases where uncarbonated depth $C>10 \mathrm{~mm}$, and the equation (2) is used in cases where $\mathrm{C} \leqq 10 \mathrm{~mm}$, and the equation (3) relates to the efficiency of temperature. In the equation (1) and (2) consider the increase of the rebar corrosion rate corresponding to the decrease of $C$ is considered, and they are non-contiguous when $C=10 \mathrm{~mm}$. In this study, the equation (2) is calculated on the assumption that $\mathrm{C}=10 \mathrm{~mm}$ in cases there $\mathrm{C}$ $>10 \mathrm{~mm}$ to ensure the continuity between the equation (1) and (2).

$$
\begin{aligned}
& V_{0}=1.32(C l-1.2) \\
& V_{0}=0.84 \mathrm{~W}-0.145 C+0.0293 \mathrm{~W} \cdot C-0.0917 C \cdot C l+0.658 C l \cdot W-2.52 \\
& V=(1+0.038(t-20)) V_{0}
\end{aligned}
$$

In here,

$V_{0}:$ rebar corrosion rate before temperature correction $\left(\mathrm{mg} / \mathrm{cm}^{2} /\right.$ year $)$

$V$ : rebar corrosion rate in consideration of temperature $\left(\mathrm{mg} / \mathrm{cm}^{2} /\right.$ year $)$

$W:$ water content of the concrete surface $(\%)$

$C$ : uncarbonated depth (mm)

$\mathrm{Cl}$ : initial chloride ion concentration $\left(\mathrm{kg} / \mathrm{m}^{3}\right)$

$t$ : temperature (degree in Celsius) (in this study, it is daily average temperature in past 5 years according to the data provided by Japan Meteorological Agency)

These equations were proposed based on experiments in constant relative humidity $(60,75,90 \%)$. For RC bridges in service, the water content of the concrete surface is difficult to estimate accurately because the environmental condition is complex. Therefore, by using this method, the water content $W_{\text {cnd }}$ is calculated. $W_{\text {cnd }}$ is related to the water received repeatedly in the past, and it will be necessary to consider more its relationship with equations (1) - (3). It is assumed that the quality of concrete is estimated by uncarbonated depth $C$, and the rebar corrosion rate depends only on the water content $W_{\text {cnd }}$.

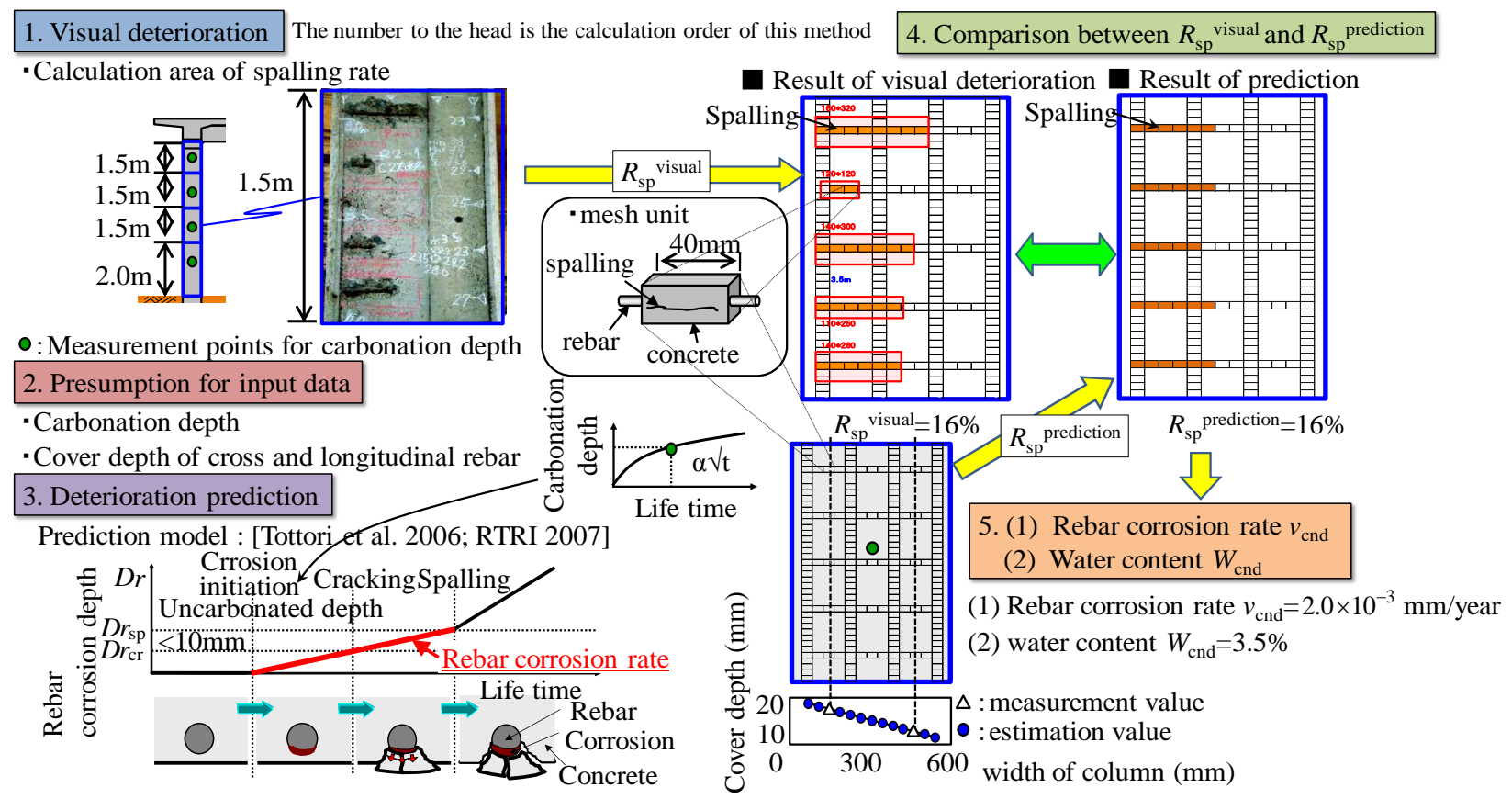

Figure 5. Summary of the Deterioration Prediction Method Based on the Visual Deterioration 


\section{Presumption of the environmental condition by visual observation and carbonation depth}

\section{Viaduct A}

Figure 6 (a) shows the average values of carbonation depths measured at the out-surface and in-surface of the left-right columns. Carbonation depths are measured only at a point $5.0 \mathrm{~m}$ under the cross beam to get rid of the effect of the column height. In addition, it shows the value calculated by using estimation equation (4) [Tanimura et al. 2004] of carbonation depth in consideration of the effect of the dry-wet condition and bleeding at the time of the construction usually taken into consideration in design. Each material constant and coefficient used for the caluculation are set as follows. Since the water per cement ratio was not recorded at the time of the construction, it was assumed to be 55\% according to design books. Two values are given to each of the coefficient of dry-wet condition and the coefficient of the quality condition of concrete by bleeding; The coefficient $\beta_{\mathrm{e}}$ expressing the degree of the effect on the environment is 1.6(dry condition) and 1.0 (wet condition), and the coefficient $\gamma_{c}$ expressing the quality of concrete is 1.3 (bleedings) and 1.0 (non-bleedings).

In here,

$$
y=(-3.57+9.0 \cdot W / C) \cdot \beta_{\mathrm{e}} \cdot \gamma_{\mathrm{c}} \cdot \sqrt{t}
$$

$y$ : carbonation depth $(\mathrm{mm})$

$\beta_{\mathrm{e}}$ : wet condition 1.3 , dry condition 1.6

$\gamma_{c}$ : bleeding 1.3 , non-bleeding 1.0

$W / C$ : water per cement ratio in concrete (in this study, it is $55 \%$ from design books)

The average value of the carbonation on the out-surface of the left column is the largest, and that on the out-surface of the right column is the smallest. The left column is under rather dry condition $\left(\beta_{\mathrm{e}}=1.6\right)$ and the right column is under rather wet condition $\left(\beta_{\mathrm{e}}=1.0\right)$ in comparison between the estimated values of the 4 cases. These results show that the out-surface of the left column is affected by sunlight and wind, and it is considered to be under a rather dry condition.

Figure 6 (b) shows the relationship between the carbonation depth of the lower part of the column measured at a point $5.0 \mathrm{~m}$ under the cross beam and the carbonation depth under the construction joint measured at a point $0.5 \mathrm{~m}$ under the cross beam. The existing paper [Tanimura et al. 2004] has reported that the carbonation depth under the construction joint due to bleeding is larger than that of the lower part of the column. This survey does not shows this tendency. There is a water-bearing mark near the upper part of the column for lack of the drainer of the cantilever beam. One of the factors causing the carbonation depth to be small at the point under the construction joint may be the effect of water from the cantilever beam.

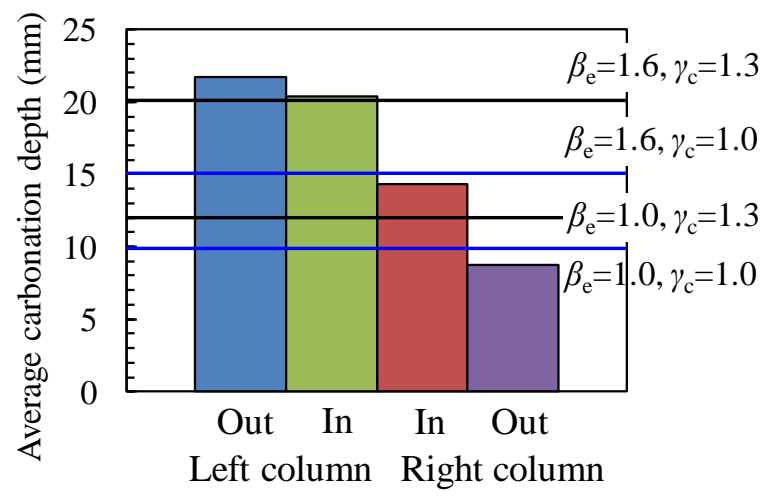

(a) Comparison between the In-out surface

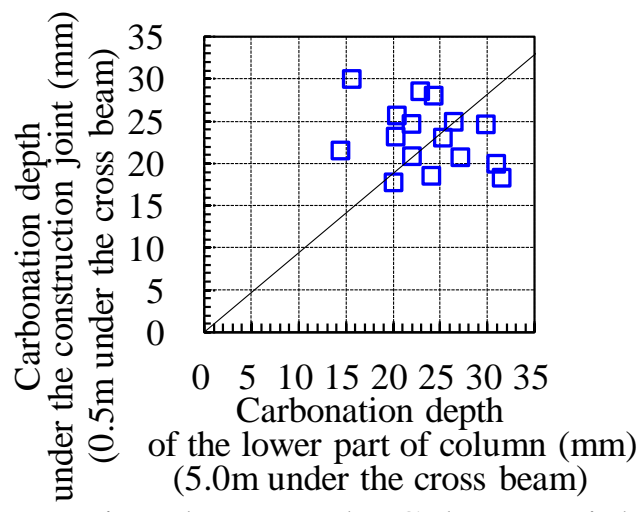

(b) Comparison between the Column Height

Figure 6. Carbonation Depth Viaduct B 
Figure 7 (a) shows the comparison of the carbonation depths between the left and right barriers. "The left and the right" are defined in the same manner as those regarding the column of viaduct A are defined. The left barrier runs from south-southwest to north-northeast and the right barrier runs from north-northeast to south-southwest. Carbonation depths of left and right barriers are almost the same, and not affected by sunlight. Figure 7 (b) shows the comparison of the carbonation depths measured at the upper-lower part of the barriers. The carbonation depth measured at the barrier top is larger than that measured at the lower part of the barrier, however, we cannot find a tendency. So, the degradation of the quality of concrete by the bleeding of the upper part of the barrier is little. The average of all measured carbonation depths is $10.4 \mathrm{~mm}$, and it is almost the same as the value of $11 \mathrm{~mm}$ which is obtained by the calculation on the assumption that $\beta_{\mathrm{e}}=1.6$ and $\gamma_{\mathrm{c}}=1.0$. Therefore, the barrier of viaduct $\mathrm{B}$ is not affected by bleeding, and it is under a rather dry condition.

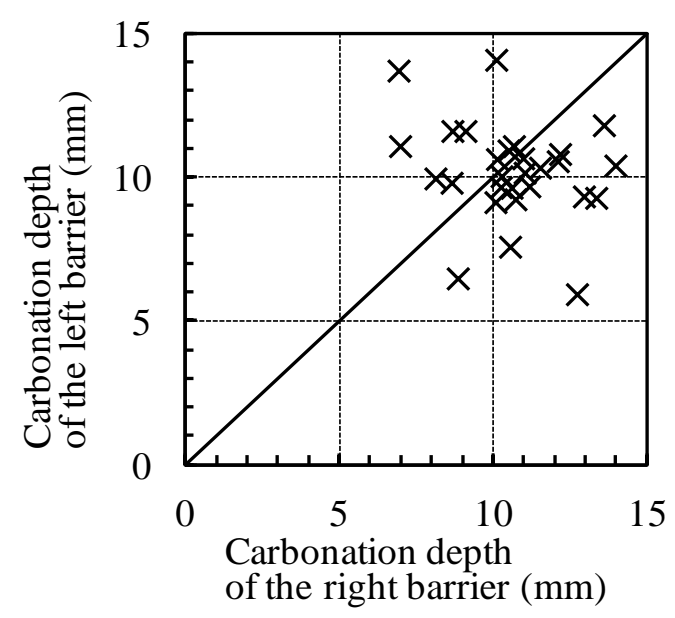

(a) Comparison between Left-Right Barrier

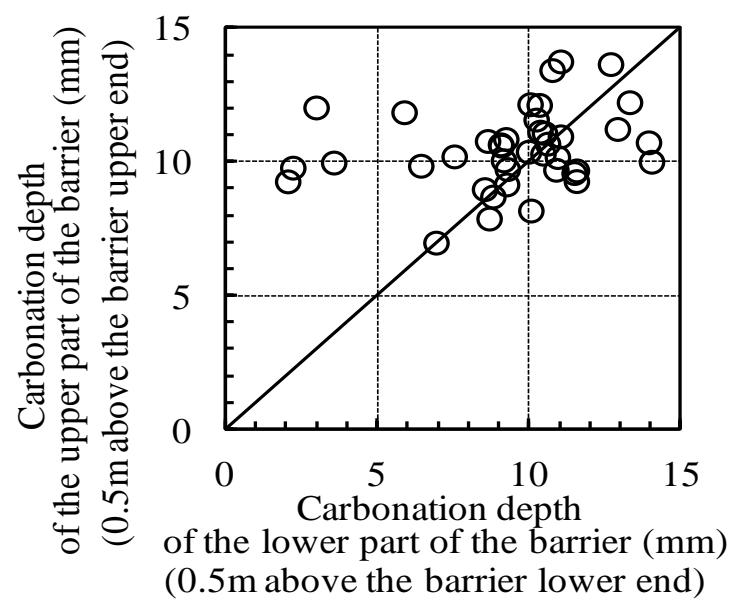

(b) Comparison between the Barrier Height

Figure 7. Carbonation Depth

\section{Study on the rebar corrosion rate estimated based on visual deterioration}

\section{Study on the rebar corrosion rate $V_{\text {cnd }}$}

In here, it is carried out for viaduct A. Figure 8 shows the relationship between the rebar corrosion rate and the column height. The number of data is 10 . In addition, the rebar corrosion rate of $3.0 \mathrm{~mm} /$ year [Tottori et al. 2006; RTRI 2007] is shown in this figure. This rebar corrosion rate is a value on the premise that it is modified according to the surrounding environment of the bridges. When the height of the column is higher, the rebar corrosion rate is larger though the number of data is too small to generalize this tendency. When considering the rebar corrosion rate according to whether the measurement point is above or below the point $1.5 \mathrm{~m}$ down from the cross bar, in cases where the height of the measurement point is $0.5-1.5 \mathrm{~m}$ below the cross bar, the rebar corrosion rate is estimated to be $3.5 \times 10^{-3} \mathrm{~mm} /$ year on average, and in cases where the height of the measurement point is $3.5-5.75 \mathrm{~m}$ below the cross bar, it is estimated to be $1.6 \times 10^{-3}$ $\mathrm{mm} /$ year on average. The rebar corrosion rate of the upper part of the column is 2.2 times as high as that of the lower part of the column.

Figure 9 shows the relationship between $v_{\text {cnd }} / v_{\text {cal }}$ and the column height. $v_{\text {cal }}$ is the calculated value by rebar corrosion rate equations (1) - (3). The temperature, which is to be more exact, daily average temperature in past 5 years past provided by Japan Meteorological Agency is 16.2degrees in Celsius. The uncarbonated depth is a measured value. The chloride ion concentration as the average value of all measured values is 
$0.23 \mathrm{~kg} / \mathrm{m}^{3}$. The water content of the concrete surface is set at 3,4,5\%. $v_{\text {cnd }} / v_{\text {cal }}$ is close to 1 when the water content of the concrete surface is $5 \%$ at a point $0.5-1.5 \mathrm{~m}$ under the cross beam, and it is close to 1 when the water content of the concrete surface is $3-4 \%$ at a point $3.5-5.75 \mathrm{~m}$ under the cross beam. Wet condition by water-bearing as presumed by visual observation and carbonation depth makes the rebar corrosion rate of the upper part of the column faster than that of the lower part of the column.

Figure 10 (a) and Figure 10 (b) show the relationship between $v_{\text {cnd }}$ and the cover depth, and between $v_{\text {cnd }}$ and the uncarbonated depth respectively. When the cover depth or the uncarbonated depth are smaller, the rebar corrosion rate is larger. But, these effects on the rebar corrosion rate is small compared with the fact that the rebar corrosion under wet condition as is abserved in the the upper part of the column is 2.2 times as large as that under dry condition as the the lower part of column. Therefore, The effect on the rebar corrosion rate of dry-wet condition is larger than that of cover depth and uncarbonated depth.



Figure 8. $v_{c n d}$ and Column Height

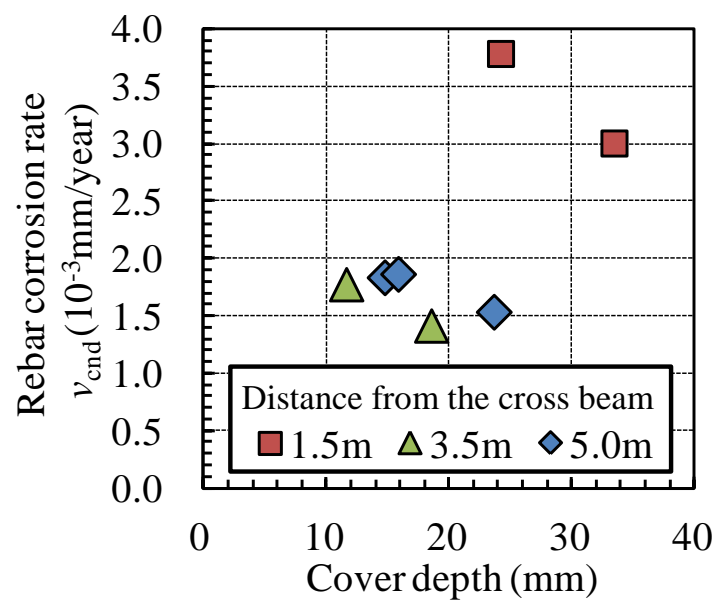

(a) Cover Depth

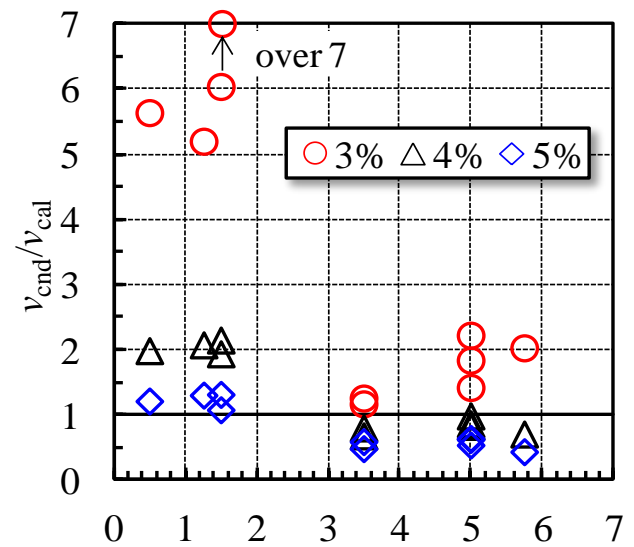

Distance from the cross beam (m)

Figure 9. $v_{\mathrm{cnd}} / v_{\mathrm{cal}}$ and Column Heithgt

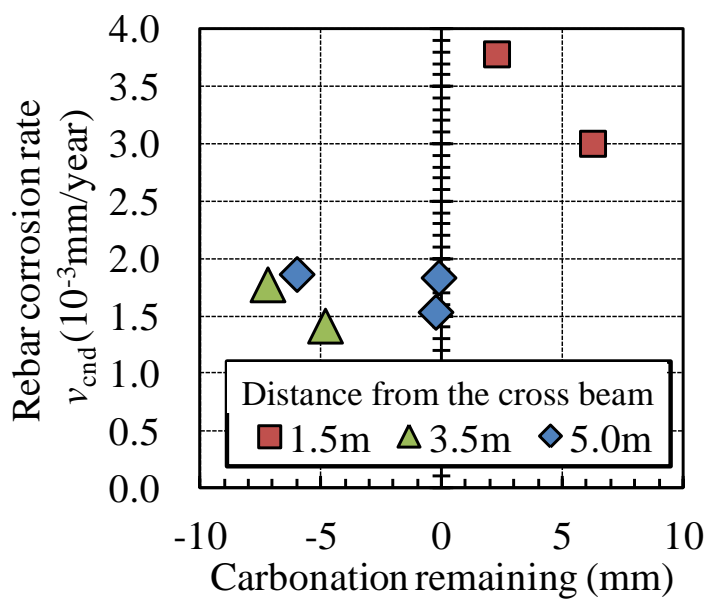

(b) Uncarbonated Depth

Figure 10. Relationship between $v_{\text {cnd }}$ and Deterioration Factors 


\section{Study on the water content $W_{\text {cnd }}$}

A study on the water content $W_{\text {cnd }}$ is performed at points where the deterioration numerously occurred on viaduct $\mathrm{A}, \mathrm{B}$. Figure 11 shows the water content. In viaduct $\mathrm{A}$, the water rate is close to $5 \%$ under wet condition at a point $0.5-1.5 \mathrm{~m}$ under the cross beam, and it is close to $3-4 \%$ under dry condition at a point $3.5-5.75 \mathrm{~m}$ under the cross beam. In viaduct $\mathrm{B}$, it is $2-3.5 \%$. In viaduct $\mathrm{B}$, water-bearing marks did not exist. $W_{\text {cnd }}$ of dry condition at a point $3.5-5.75 \mathrm{~m}$ under the cross beam of viaduct $\mathrm{A}$ is larger than that of viaduct $B$. This reason is that the annual average precipitation around viaduct $A$ is more than that around viaduct $\mathrm{B}$. Therefore, $W_{\text {cnd }}$ in the equation (2) is about $5 \%$ at the points of water-bearing that are always under wet condition, and it is $2-4 \%$ at points that are always under dry condition or dry-wet condition according to the annual average precipitation.

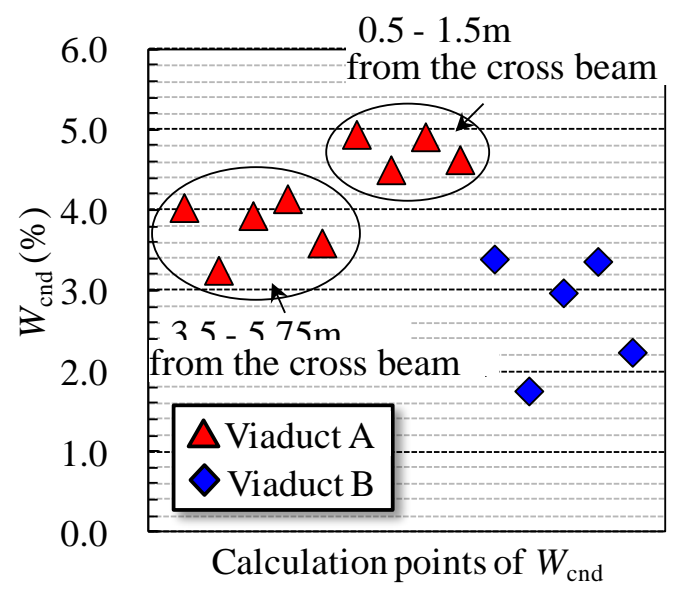

Figure 11. Water Content $W_{\text {cnd }}$

\section{Prediction for the initiation of the spalling of cover concrete}

The estimated rebar corrosion $v_{\text {cnd }}$ is used to predict the initiation of the spalling of cover concrete. Figure 12 shows the result of the prediction for viaduct A. R2C1 shown in Figure 12 (a) is the bridge number and the column number shown in Figure 1, and Left-End-5.0 means a left column, the end surface and a measurement point $5 \mathrm{~m}$ down from the cross beam. R2C3 Left-Out-0.5 shown in Figure12 (b) also means the same. This result indicates that the spalling of the cover concrete will rapidly occur and the cumulative probability of the occurrence of the spalling will reach $40-60 \% 20$ years later.

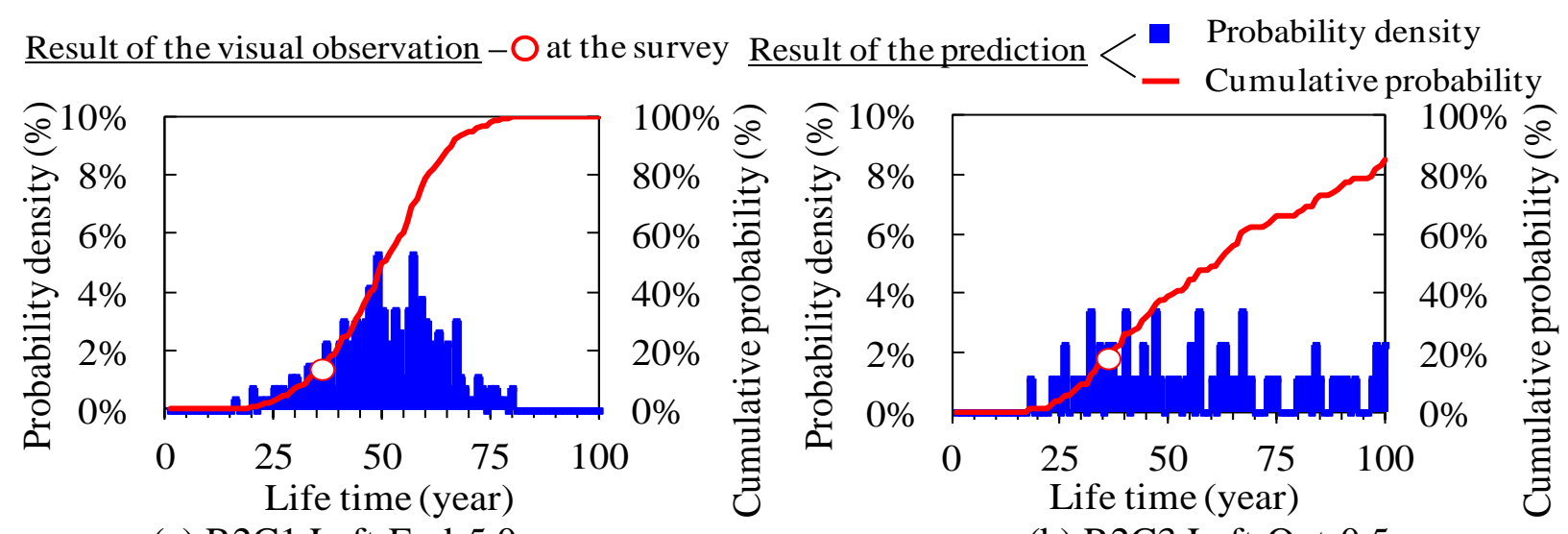

(a) R2C1 Left-End-5.0

(b) R2C3 Left-Out-0.5

Figure 12. Prediction of the Spalling Rate (e.g. Viaduct A) 
Figure 13 shows the time-series simulation for the initiation of the spalling of cover concrete. Figure13(a) is the result 36 years after the construction of the viaduct, which is the age of the viaduct at the time of survey, and Figure13(b) is the result 100 years after its construction. In here, the rebar corrosion rate of $3.5 \times 10^{-3} \mathrm{~mm} /$ year is used at a point $0.5-1.5 \mathrm{~m}$ and $1.6 \times 10^{-3} \mathrm{~mm} /$ year at a point $1.5-5.75 \mathrm{~m}$ under the cross beam. The contour level indicates the rebar corrosion amount. This result suggests when and where the survey should be conducted and the countermeasures should be taken.

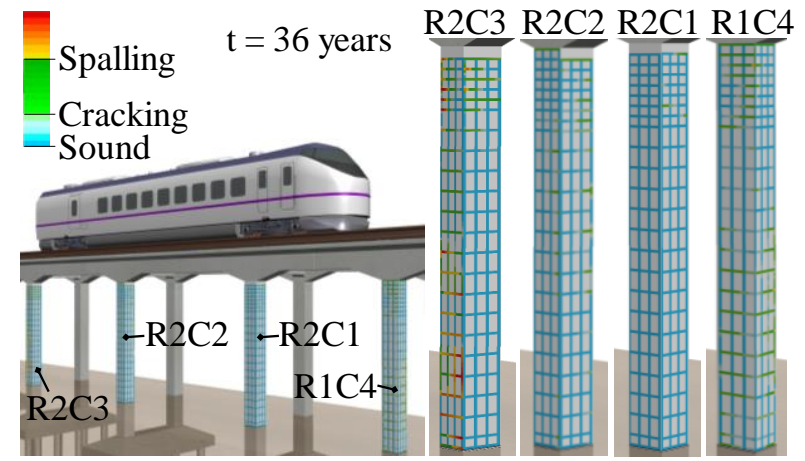

(a) 36 years at the Time of the Survey

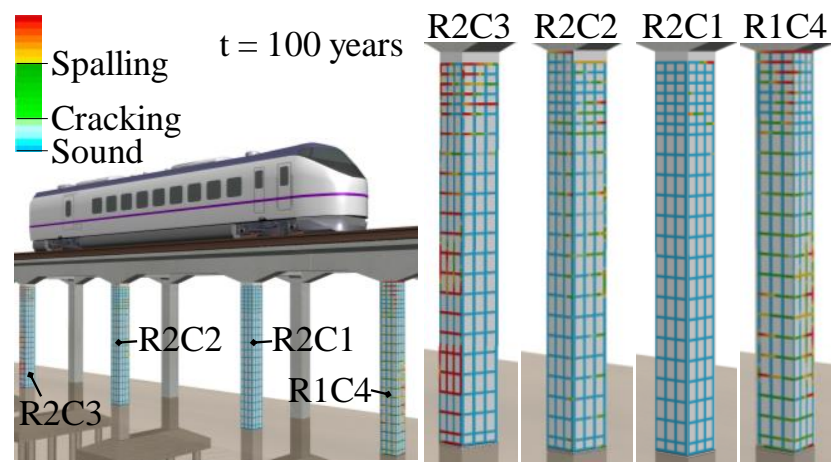

(b) 100 years

\section{Figure 13. Time-Series Simulation of the Spalling of Cover Concrete (e.g. Viaduct A)}

\section{CONCLUSION}

- The rebar corrosion rate of wet condition is 2.2 times faster than that of dry condition.

- The effect of dry-wet condition on the rebar corrosion rate is larger than that of cover depth and uncarbonation depth.

- When using the existing rebar corrosion rate equation in consideration of the water condition of concrete, the water content of the concrete surface is about $5 \%$ at the point under wet condition such that a water-bearing mark is abserved, and it is about $2-4 \%$ at the point under dry condition.

\section{REFERENCES}

Iijima, T., Kudo, T. and Tamai, Y. (2009) "Effect of Temperature on Corrosion Rate of Reinforcing Bar in Concrete", Tetsudo Souken Houkoku, Vol.23, No.6, 11-16.

Kakegawa, M., Masuda, Y., Matsubayashi, Y., and Kage, T. (2012) "Long-Term Outdoor Exposure Test on the Rate of Corrosion of Reinforcing Bar in Concrete Containing Chloride Ion", Journal of Structural and Construction Engineering(Transactions of AIJ), Vol.77, No.672, 143-151.

Maekawa, K., Ishida, T., and Kishi, T. (2008) "Multi-scale Modeling of Concrete Performance" Taylor and Francis.

Maruya, T., Takeda, H., Horiguti, K., Koyama, S., and Hsu, K (2006) "Simulation of Steel Corrosion in Concrete Based on the Model of Macro-Cell Corrosion Circuit", Journal of materials, Concrete Structures and Pavements, Vol.62, No.4, 757-776.

Railway Technical Research Institute. (2007) "Maintenance Standards for Railway Structures and Commentary (Structure part) Concrete Structure", Maruzen, 222-233.

Tanimura, Y., Hasegawa, M., Sogabe, M., and Sato, T. (2004) "Durability Evaluation Method of Carbonation For Railway RC Rigid Frame Viaducts" Journal of materials, Concrete Structures and Pavements, Vol.760/V-63, 147-157.

Tottori, S., and Miyagawa, T. (2004) "Deterioration Prediction of Concrete Structures Concerning Rebar Corrosion due to Carbonation" Journal of materials, Concrete Structures and Pavements, Vol.767/V64, 35-46. 